\title{
Cultural and Religious Tolerance and Acceptance in Urban Housing: A Study of Multi-Ethnic Malaysia
}

\author{
Azrina Husin (Corresponding author), Nor Malina Malek \& Salfarina Abdul Gapor \\ School of Social Sciences, Universiti Sains Malaysia \\ 11800 Pulau Pinang, Malaysia \\ Tel: 60-4-653-4614 E-mail: azrina@usm.my
}

Received: August 3, 2011

Accepted: September 15, 2011

Published: February 1, 2012

doi:10.5539/ass.v8n2p112

URL: http://dx.doi.org/10.5539/ass.v8n2p112

\begin{abstract}
This paper attempts to describe some housing issues pertaining to religious and cultural practices in Malaysia. As a multi-ethnic and multi-cultural society, residential arrangements are used as a tool to achieve greater social and ethnic mix as envisioned by the government under the New Economic Policy and its Housing Policy. While the aim is for social integration among its population, living with people who do not share similar cultural and religious practices may cause problems too, especially that related to the use of space. This is especially true in urban housing areas where space is scarce and thus does not always cater to the residents' needs. Using a sample of 400 respondents from four urbanized areas of Penang, Kuala Lumpur, Selangor and Johor Bahru, we try to understand the respondents' views about their neighbours' religious and cultural practices that differ from theirs. Our findings will be discussed within the framework of cultural acceptance and tolerance as well as to gauge whether the government's policy is translated well by the population.
\end{abstract}

Keywords: Urban living, Cultural acceptance, Cultural tolerance, Malaysia

\section{Introduction}

An ethnically diverse society faces the challenge of maintaining, if not fully achieving, harmonious relations among its population. In the case of multi-ethnic Malaysia, its society is further divided in terms of language, customs and religions. That stable ethnic relations is one of the key ingredients to political and economical stability is not mere exaggeration. Indeed, Malaysia faced its worst ethnic conflict in 1969 that shook the country and forced the government to abandon the fairly laissez faire policy it had adopted since independence in 1957 with regards to ethnic relations and economic growth. Malaysia's plural society is a legacy inherited from the British rule of the country. During this colonial period, the local Malays who made up the majority of the country's population resided in the rural areas where their economic activities revolved mainly around small-scale farming, far removed from the colonial economic activities (Syed Husin Alatas 1977). On the other hand, the Chinese and Indians who were brought into then-Malaya to provide labor to the key sectors such as mining and large-scale plantations dwelled in what later developed into small towns and cities. This living pattern persisted well until the country achieved its independence in 1957, creating an urban-rural gap with a racial undertone. Precisely because a group's geographical location will in turn determine its access to major economic activities and ultimately a share of the nation's wealth, feelings of inequality, dissatisfaction and marginalization were high among the Malays culminating in the above mentioned racial riot. This incident proved that the country had a lot to lose unless the disparity, not only in wealth, but also access to important economic activities among its major ethnic groups was properly (and sensitively) tackled. With the introduction of the New Economic Policy in 1971, the government proactively seek to restructure society so as to achieve social integration as well as to eradicate poverty.

One area in which this policy was used is the urban residential pattern. Housing is then viewed as a tool for fostering better social relations among the various ethnic groups by enforcing a quota system in the allocation of houses (or units) in urban residential areas with the aim of achieving a more "balanced" ethnic mix. According to this formula, all housing projects undertaken by the private sector will have a mixture of all types of housing, including low cost and medium cost houses. In addition, there must be allocation of units according to ethnic groups in order to encourage the Malays to own housing units in urban areas. In this way, it is hoped that in the 
long run residential segregation would be eliminated, interaction opportunities among these various ethnic groups would be created thus achieving better understanding of one another which in turn would keep the ethnic relations in the country relatively stable and harmonious.

Given this background, it is important to understand the views of urban Malaysians with regards to their neighbours especially in terms of their acceptance of different cultural and religious practices. Choosing a residence is not merely a simple choice of housing type, but embedded in this choice is also the kind of environment that a chosen residential has to offer which include health, security, privacy, location and amenities. This paper seeks to see whether cultural differences affect residential choice among urban dwellers, ultimately aiming at an understanding whether Malaysians are tolerant and acceptable of the cultural diversity that marks its society.

\subsection{Housing and Ethnicity}

The vast literature on housing shows that there are empirical evidences to support the relationship between housing and ethnicity with the latter having a strong bearing in many aspects of housing. Available data in America shows that homeownerships among White households far exceed that of minority groups such as the Blacks and Hispanics although the gap between the Whites and these minority groups has improved over the years (Boehm and Schlottmann 2008). Time taken to own a house also differ between White households and other minority households, with the former taking lesser time than its counterpart. Racial differences also exist in terms of house ownership between wealth-constrained whites and other minority groups (Gyourko et al. 1999). The contributing factors to this differences are many such as discrimination faced by the Blacks with lenders and property brokers as opposed to whites (Yinger 1995), limiting their choices of houses and neighbourhood. Building from the vast literature, Boehm and Schlottmann (2004) have shown that in addition to a limited progression beyond first-time ownership of houses, minority families in the lower income category also show a higher probability of falling back to renting after owning a place, a trend that they found absent among the White households. They have also demonstrated that different ethnic groups not only have different understanding and access to financial institution in helping them with homeownership, but their housing issues as well as needs also differ, thus calling for a need-based and ethnically sensitive housing policy in America.

\subsection{Ethnic Relations, Cultural Acceptance and Cultural Tolerance}

While in general people may prefer living among those from their own ethnic group (Yinger 1976), residential segregation by race not only divides society it also hinders interaction between groups leading to mistrust (Peach 1996). Migration, both within and across borders, resulted in people from diverse background having to live in the same location. They were further faced with the challenge of tolerance and acceptance of the differences. Due to concerns about the negative implications of the concentration of minority ethnic groups to certain areas in the city, many countries have implemented state-level intervention in order to disperse these groups to other parts of the city. In Britain, for example, the black migrants were spread out among the white population by the city council under its dispersal policies (Phillips and Karn 1991). Neighboring city-state Singapore also imposed an ethnic quota policy whereby concentration of one ethnic group in any residential areas is deterred (Chih 2002), using housing as a social engineering tool (Tremewan 1996), with the aim of achieving a good social mix and a balanced community. This approach to social engineering is certainly not that different than the one espoused by the Malaysian government.

A diverse community of ethnicity, class and origins is believed to be better able at promoting interaction and understanding among its inhabitants whereby the residents accept and tolerate each others' differences. However, there are studies that show the contrary. Kuper (1953), for example, demonstrated that a community of different economic and social background may in fact be at odds with each other as tolerance and acceptance may be difficult to achieve, precisely due to the differences. This has led Cole and Goodchild (2001), among others, to question the rationale of social mix in housing policies of urban areas.

\subsection{Housing Issues in Malaysia}

Malaysian housing development is governed by the Malaysian Housing Policy which was developed when the country gained its independence in 1957. With the changing of time, the policy has also evolved in terms of its focus and emphasis. This policy has tried to overcome the problem of urban squatters and slums resulted from the phenomenon of rural to urban migration, especially in the 1970s and 1980s. Added to these, the policy also addresses the issue of providing cheaper yet better quality houses. Over the years, the policy stresses on housing ownership among Malaysians, in particular among those in the low-income bracket group, viewing housing as a basic need for its population. With the introduction of the New Economic Policy (NEP) discussed above, the 
policy seeks to address the imbalance among the ethnic groups in terms of house ownership as well as seeing housing as a tool towards achieving racial harmony.

While the government continues to provide affordable houses under the public housing programs, the housing policy also requires the private developers to include the building of low cost housing in their housing development plan. In this way, house ownership of the less privileged population is a shared responsibility between the public and private sectors. However, as the country develops economically, the size of its middle income population also increases. The challenges for the government now is to provide affordable and conducive housing for its middle income population especially in urban areas such as Penang and Kuala Lumpur as the property market has skyrocketed in the past few years.

With this background, studies on housing issues in the country have also shifted in its focus. In the early 1980s, focus was given on the issue of rural-urban migration especially among the Malays and its implication on urban settlements among this ethnic group. Mohd. Razali Agus (1989; 1993), for example, looked at issues of home ownership among low income Malays and their squatter settlement problems and its effects on urban landscape. On the other hand, a more recent study conducted by Abdul Ghani Salleh (2008) looked at satisfaction levels with neighbourhood qualities among dwellers in various states in Malaysia.

\section{Data}

The data for this study was derived from 400 households in four urban areas of Penang, Kuala Lumpur, Selangor and Johor Bahru. A cluster sampling focussing on the four areas was conducted, targeting at 100 respondents for each area. In addition to this, a stratified random sampling based on ethnicity (Malay, Chinese and Indian) and types of housing (low cost and medium cost housing) was also applied to the sample. As shown in Table 1, the actual numbers of respondents do not meet the targeted numbers, with low response rate from the Chinese. With regards to the types of housing, the data yielded 30 respondents from high cost housing, 99 and 267 respondents from the low cost and medium cost housing respectively.

A standardized, six-part questionnaire was used as a tool for data collection. The questionnaire was designed to tap into the respondents' socio-economic background and housing information. Added to this, the questionnaire also focuses on the respondents' perceptions on their own housing units, the areas surrounding their housing units as well as their neighbours. Once the data was collected, frequency tests were conducted for the main items in the questionnaire. For the purpose of this paper, questions that are used to measure respondents' tolerance and acceptance of their neighbours' culture revolve around issues such as their interaction with their neighbours, knowledge about as well as acceptance of the neighbours' cultural and religious practices.

\section{Results and Discussions}

\subsection{Respondents' Background}

The demographic background of the respondents who participated in this study is shown in Table 2. With regards to the four areas, slightly more than half of the sample came from both Penang and Johor Bahru. Although Kuala Lumpur is arguably the most urban of these four areas, it only made up about $20 \%$ of the sample. The ethnic distribution of the sample more or less represented the ethnic mix of the population of $60 \%$ Malays, $25 \%$ Chinese and $10 \%$ Indians. The ethnic breakdown also reflected the religious breakdown of the respondents, with about one third Muslims (very likely Malays), 16\% Buddhists (likely Chinese), 10\% Hindu (likely Indians) and Christians (likely Chinese and Indians). In addition to ethnic groups and religions, the data from this study was derived predominantly from married respondents as opposed to singles.

The survey also tapped into the respondents' income, educational level as well as whether they are self-employed, working in the private or government sectors as it is posited that these factors will affect issues pertaining to urban housing such as period of house ownership, housing affordability as well as availability of housing funds. As shown in Table 3, the respondents of this study are well-educated with $50 \%$ of them having completed tertiary education and only a small $5 \%$ of the respondents either did not attend school or only finished primary level education. More than two-third of the respondents have a household income above RM2,000, placing these households above the urban poverty level of RM1,500 as stated by the government.

\subsection{Ethnic Composition vs. Price in House Purchasing}

Existing literatures on housing have shown that there are many factors potential buyers take into consideration before purchasing a housing unit. This is due to the fact that house ownership provides some form of security to the owners. Others, on the other hand, may view it as a lucrative investment. Out of seven factors given in the questionnaire, respondents were asked to choose one factor that they consider to be of the upmost importance in their decision to buy a housing unit. The result, shown in Table 4, revealed that the ethnic composition of a 
location is ranked last, with only $1.8 \%$ of the total 400 respondents taking it to be the major consideration in their purchasing decision. Price and location are the most important considerations for these respondents, reflecting issues of affordability and good location of the housing units. In fact, it is revealed that $66.8 \%$ of the respondents own medium-cost houses, priced below RM200,000. These two factors were also ranked the top two when asked to identify the main problems they faced when buying their housing units, with $40 \%$ and $33 \%$ of the respondents citing price and location respectively. In terms of financing method, the study found that $70.5 \%$ of the respondents had relied on housing loans made available from the various commercial banks while only a mere $10 \%$ saved up to own their houses. Thus, while ethnic composition of a location may affect day-to-day practices and concerns, housing prices still weight a lot heavier for these respondents.

\subsection{Interactions and Perceptions of their Neighbours}

Essentially, the results in the previous section point to the fact that these respondents accept that urban living entails living with people of different ethnic and cultural background. Thus, it is important for us to find out how much these respondents know of their neighbours and how they view the cultural and religious practices of their neighbours, especially those that differ from their own. Table 5 shows the results of six items used to gauge respondents' cultural tolerance and acceptance with regards to their neighbours' cultural practices. All 400 respondents were able to identify the religion and ethnicity of their neighbours, implying that even if there is minimum level of interaction, they are still able to know who their neighbours are. However, more importantly, the result shows that $76 \%$ of the total respondents interact with their neighbours, negating the myth of atomized and individualized urban living. In fact, almost the same figure accepts invitations from their neighbours. With regards to their acceptance of their neighbours' cultural and religious practices, about two thirds of the respondents in this study indicated their acceptance.

\subsection{Ethnic Preference}

As discussed earlier, under the Malaysian Housing Policy, an urban residential area in the country has the potential to serve as a meeting point for its diverse ethnic groups. Due to the issue of affordability in the rise of the property market, ethnic composition takes a back seat in buyers' purchasing consideration. While the respondents show a positive identification with their neighbours, in terms of knowing and accepting their neighbours' cultural and religious practices, almost $50 \%$ of them would prefer to live among people from the same ethnic group. $36 \%$ of the respondents do not mind the ethnicity of their neighbours, while a small $14 \%$ of them do not prefer to live with the same neighbourhood with their ethnic groups. The results are shown in Table 6. Certainly, this is assuring to know as it somewhat indicates quite a high level of tolerance among Malaysians of the cultural and religious practices of others.

When probed further on ethnic preference, the results in Table 7 show that more than $70 \%$ of the respondents were willing to live with certain ethnic groups and not another. On the other hand, $14 \%$ of them are ethnic blind in the sense that they do not mind what ethnicity their neighbours' belong to, while $12 \%$ of the respondents indicated that given a choice they wish to live among people from the same ethnic group as they are. This finding in turn agrees with Yinger (1976) in that people prefer to live with their own ethnic groups, or at least in this study, people do not mind living with a group that shares similar cultural and religious practices as them. A Chinese family may find it easier to live next to an Indian family as opposed to a Malay family as their everyday practices, like a keeping a dog, do not go against one another. While this finding can also be interpreted as uneasiness to be with those different than us, it can also mean conflict avoidance with those different from them, and at a certain level, an understanding and acceptance of one's differences.

\section{Conclusion}

Tolerance and acceptance of cultural and religious practices that differ from one's own is crucial in a diverse society like Malaysia. Without these, the stability of the country will be at stake. The results discussed in this paper show that, in general, cultural and religious differences among Malays, Chinese and Indians are not a deterrent factor in their choice of housing. It certainly points to some level of tolerance and acceptance towards their neighbours' cultural and religious practices. Put differently, Malaysians are willing to live with other ethnic groups with cultural and religious practices different from them. While this can also be attributed to the top-down policy of ethnic and social mix in urban areas by the state, Malaysian urban dwellers in general do not see cultural difference as a big issue of concern because when it comes to purchasing of housing, there are much bigger issues at play which are prices and locations of housing units.

\section{Acknowledgements}

The authors would like to express their appreciation to the Universiti Sains Malaysia, Penang, Malaysia for the grant made available for this study from 2007 to 2010 under the Research University (RU) Grant Scheme. 


\section{References}

Abdul Ghani Salleh. (2008). Neighbourhood Factors in Private Low-cost Housing in Malaysia. Habitat International, 32, pp. 485-493. http://dx.doi.org/10.1016/j.habitatint.2008.01.002

Boehm, T. P. and Schlottmann, A. M. (2004). The Dynamics of Race, Income, and Homeownership. Journal of Urban Economics, 55, pp. 113-130. http://dx.doi.org/10.1016/j.jue.2003.08.001

Boehm, T. P. and Schlottmann, A. M. (2008). Housing Tenure, Expenditure and Satisfaction across Hispanic, African-American and White Households: Evidence from the American Housing Survey. Cityscape: A Journal of Policy Development and Research, 10(2), pp. 95-158.

Chih Hoong Sin. (2002). The Quest for a Balanced Ethnic Mix: Singapore's Ethnic Quota Policy Examined. Urban Studies, (39)8, 1347-1374. http://dx.doi.org/10.1080/00420980220142673

Cole, I. and Goodchild, B. (2001). Social Mix and the 'Balanced Community' in British Housing Policy-A Tale of Two Epochs. GeoJournal, 51, 351-360. http://dx.doi.org/10.1023/A:1012049526513

Gyourko, J. P., Linnemann, P. and Wachter, S. (1999). Analyzing the Relationship among Race, Wealth, and Home Ownership in America. Journal of Housing Economics, 8, pp. 63-89. http://dx.doi.org/10.1006/jhec.1999.0242

Kuper, L. (1953). Blueprint for living together. Kuper, L. (ed.). Living in Towns. Cresset Press: London.

Mohd. Razali Agus. (1989). Impact of Urbanization on the Urban Malays and Malaysia: Problems of Homeownership of the Lower Income Groups. Sarjana, 5, pp. 113-142.

Mohd. Razali Agus. (1993). Squatters and Urban Development in Malaysia. Sarjana, 10, pp. 113-131.

Peach, C. (1996). Good Segregation, Bad segregation. Planning Perspectives, 11, pp. 379-398. http://dx.doi.org/10.1080/026654396364817

Phillips, D. and Karn, V. (1991). Racial Segregation in Britain: Patterns, Processes, and Policy Approached, In Huttman, E. D. (ed.) Urban Housing Segregation of Minorities in Western Europe and the United States. Durham, NC: Duke University Press.

Syed Hussein Alatas. (1977). The Myth of the Lazy Native. London: Frank Cass and Co.

Tremewan, C. (1996). The Political Economy of Social Control in Singapore, $2^{\text {nd }}$ ed. London: Macmillan Press.

Yinger, J. (1976). Racial Prejudice and Racial Residential Segregation in an Urban Mode. Journal of Urban Economics, 3, pp. 383-406. http://dx.doi.org/10.1016/0094-1190(76)90037-1

Yinger, J. (1995). Closed Doors, Opportunities Lost: The Continuing Costs of Housing Discrimination. New York: Sage.

Table 1. Sampling of targeted and actual respondents based on location, ethnicity and types of housing

\begin{tabular}{|clcc|}
\hline & & Target & Actual \\
\hline States & Penang & 100 & 122 \\
& Kuala Lumpur & 100 & 79 \\
& Selangor & 100 & 96 \\
& Johor & 100 & 103 \\
& $\quad$ Total & 400 & 400 \\
\hline Ethnic & Malay & 200 & 248 \\
& Indian & 68 & 101 \\
& Chinese & 132 & 45 \\
& Others & 0 & 6 \\
& Total & 400 & 400 \\
\hline Type of houses & High cost & - & 30 \\
& Low cost & 200 & 99 \\
& Medium cost & 200 & 267 \\
& Other & - & 4 \\
& Total & 400 & 400 \\
\hline
\end{tabular}


Table 2. Demographic background of the respondents

\begin{tabular}{|c|c|c|c|}
\hline & & Frequency & Percentage \\
\hline \multirow{5}{*}{ Areas } & Penang & 122 & 30.5 \\
\hline & Kuala Lumpur & 79 & 19.8 \\
\hline & Selangor & 96 & 24 \\
\hline & Johor Bahru & 103 & 25.8 \\
\hline & Total & 400 & 100 \\
\hline \multirow[t]{3}{*}{ Gender } & Male & 265 & 66.3 \\
\hline & Female & 135 & 33.8 \\
\hline & Total & 400 & 100 \\
\hline \multirow[t]{5}{*}{ Ethnic } & Malay & 248 & 62 \\
\hline & Chinese & 101 & 25.3 \\
\hline & Indian & 45 & 11.3 \\
\hline & Others & 6 & 1.5 \\
\hline & Total & 400 & 100 \\
\hline \multirow[t]{6}{*}{ Religion } & Islam & 251 & 62.8 \\
\hline & Buddha & 65 & 16.3 \\
\hline & Hindu & 41 & 10.3 \\
\hline & Christian & 42 & 10.5 \\
\hline & Others & 1 & 0.3 \\
\hline & Total & 400 & 100 \\
\hline \multirow{4}{*}{$\begin{array}{l}\text { Marital } \\
\text { Status }\end{array}$} & Single & 77 & 19.3 \\
\hline & Married & 306 & 76.5 \\
\hline & Others & 17 & 4.2 \\
\hline & Total & 400 & 100 \\
\hline
\end{tabular}

Table 3. Socio-economic background of the respondents

\begin{tabular}{|c|c|c|c|}
\hline & & Frequency & Percentage \\
\hline \multirow[t]{6}{*}{ Educational Level } & Never attended school & 5 & 1.3 \\
\hline & Primary school & 17 & 4.3 \\
\hline & University & 142 & 35.5 \\
\hline & Secondary school & 153 & 38.3 \\
\hline & College & 83 & 20.8 \\
\hline & Total & 400 & 100 \\
\hline \multirow[t]{5}{*}{ Employer Sector } & Government & 61 & 15.3 \\
\hline & Self-employed & 71 & 17.8 \\
\hline & Private & 250 & 62.5 \\
\hline & Others & 18 & 4.5 \\
\hline & Total & 400 & 100 \\
\hline \multirow[t]{4}{*}{ Household Income } & RM 1000 and below & 44 & 11 \\
\hline & RM 1001-2000 & 78 & 19.5 \\
\hline & RM 2001-3000 & 87 & 21.8 \\
\hline & RM 3001-4000 & 82 & 20.5 \\
\hline
\end{tabular}




\begin{tabular}{|l|l|r|r|}
\hline & RM 4001-5000 & 48 & 12 \\
\cline { 2 - 4 } & RM 5001 and above & 61 & 15.3 \\
\hline & Total & $\mathbf{4 0 0}$ & $\mathbf{1 0 0}$ \\
\hline
\end{tabular}

Table 4. Main factors to consider when buying a house

\begin{tabular}{|c|c|c|}
\hline Factors & Frequency & Percentage (\%) \\
\hline Price & 145 & 36.3 \\
\hline Location & 110 & 27.5 \\
\hline Design & 16 & 4.0 \\
\hline Ethnic composition & 7 & 1.8 \\
\hline Build-up area & 42 & 10.5 \\
\hline Distance from work place & 47 & 11.8 \\
\hline Public amenities & 33 & 8.3 \\
\hline Total & 400 & 100 \\
\hline
\end{tabular}

Table 5. Respondents' relationship with their neighbours

\begin{tabular}{|l|c|c|}
\hline \multicolumn{1}{|c|}{$\begin{array}{c}\text { Relationship between the respondents and their } \\
\text { neighbours }\end{array}$} & Frequency & Percentage (\%) \\
\hline Able to identify ethnicity of neighbour & 400 & 100 \\
\hline Able to identify religion of neighbour & 400 & 100 \\
\hline Interact with neighbour & 305 & 76.3 \\
\hline Accept invitation from neighbour & 309 & 77.3 \\
\hline Acceptance of neighbour's cultural practice & 246 & 61.5 \\
\hline Acceptance of neighbour's religious practice & 261 & 65.3 \\
\hline
\end{tabular}

Table 6. Preference to live with same ethnic group

\begin{tabular}{|l|r|r|}
\hline & Frequency & \multicolumn{1}{|c|}{ Percent } \\
\hline Yes & 195 & 48.8 \\
\hline No & 58 & 14.5 \\
\hline Do not mind & 147 & 36.8 \\
\hline Total & $\mathbf{4 0 0}$ & $\mathbf{1 0 0 . 0}$ \\
\hline
\end{tabular}

Table 7. Ethnic preference

\begin{tabular}{|l|c|c|}
\hline & Frequency & Percent \\
\hline Willing to live with certain ethnic group & 296 & 74.2 \\
\hline Willing to live with any ethnic group & 56 & 14.0 \\
\hline Must live with same ethnic group & 48 & 12.0 \\
\hline \multicolumn{1}{|c|}{ Total } & $\mathbf{4 0 0}$ & $\mathbf{1 0 0 . 0}$ \\
\hline
\end{tabular}

